\title{
A Preliminary Study of Biodegradable Waste as Sorbent Material for Oil-Spill Cleanup
}

\author{
J. Idris, ${ }^{1}$ G. D. Eyu, ${ }^{1}$ A. M. Mansor, ${ }^{1}$ Z. Ahmad, ${ }^{2}$ and C. S. Chukwuekezie ${ }^{1}$ \\ ${ }^{1}$ Faculty of Mechanical Engineering, Universiti Teknologi Malaysia, Skudai, Johor Bahru 81310, Malaysia \\ ${ }^{2}$ ISI, Universiti Teknologi Malaysia, Skudai, Johor Bahru 81310, Malaysia \\ Correspondence should be addressed to G. D. Eyu; feldeg2002@yahoo.com
}

Received 7 November 2013; Accepted 8 January 2014; Published 11 February 2014

Academic Editors: T. H. D. Flores-Sahagun and N. Voulvoulis

Copyright (c) $2014 \mathrm{~J}$. Idris et al. This is an open access article distributed under the Creative Commons Attribution License, which permits unrestricted use, distribution, and reproduction in any medium, provided the original work is properly cited.

\begin{abstract}
Oil spill constitutes a major source of fresh and seawater pollution as a result of accidental discharge from tankers, marine engines, and underwater pipes. Therefore, the need for cost-effective and environmental friendly sorbent materials for oil spill cleanup cannot be overemphasized. The present work focuses on the preliminary study of empty palm fruit bunch fibre as a promising sorbent material. The morphology of the unmodified empty palm fruit bunch, EPFB fibre, was examined using an optical microcopy, scanning electron microcopy coupled with EDX and X-ray diffraction. The effects of oil volume, fibre weight, and time on oil absorption of EPFB fibre were evaluated with new engine oil from the model oil. The results show that EPFB fibre consists of numerous micro pores, hydrophobic, and partially crystalline and amorphous with approximately $13.5 \%$ carbon. The oil absorbency of the fibre increased with the increase in oil volume, immersion time, and fibre weight. However, sorption capacity decreased beyond $3 \mathrm{~g}$ in $100 \mathrm{~mL}$. Additionally unmodified EPFB fibre showed optimum oil sorption efficiency of approximately $2.8 \mathrm{~g} / \mathrm{g}$ within three days of immersion time.
\end{abstract}

\section{Introduction}

Sorbents are materials with high attractions for oil and repellent for water. Sorbent materials remove oil by two mechanisms. These can either be done by adsorption or absorption. Adsorption involves the adherence of oil to the sorbent material which is dependent upon the viscosity of the oil. The more viscous the oil, the thicker the layer that will adhere to a given material. On the other hand, absorption relies on capillary attraction; oil fills the pores within the material and moves upward (uptake) into the material due to capillary force. Sorbent can be grouped as inorganic minerals and synthetic, organic, and organic (agricultural) products. Agricultural sorbents are cheap, efficient, environmentally friendly, and easy to deploy. However, efficiency is dependent on sorption capacity, density, wettability, retention rate and recyclability $[1,2]$, and examples are cotton, straws, corn cobs, coconut shells, kenaf, kapok fibres, rice husk, and silkworm cocoon, hay, sawdust, bagasses, gorse, and dried palm fronds [3-6].These materials are oleophilic because of their waxy nature, they become light weight when dried, which improves their buoyancy in water. Straw has been the most widely and probably the most efficient of all these materials. Straw fibres can float on the water surface for a very long period of time to collect oil adequately. It has been reported that straw sorption capacity is higher than commercial synthetic organic material from propylene [7]. Similarly, kapok, rice husk, banana trunk fibre, acetylation of raw cotton, and cotton grass fibre, have been reported to be efficient as oil sorbents [8-13].

Malaysia is the world largest palm oil fruit producer. The palm plantations form an enormous source of fibrous biomass [14]. The empty fruit bunches are normally considered as an agricultural waste and usually left to naturally decompose or dispose at a land fill; this poses environmental challenge. The use of date palm activated carbon as sorbent has been reported [15]. However, very limited study of the use of empty fruit bunch fibre as oil sorbent and factors affecting 
TABle 1: Properties of liquid used in experiment.

\begin{tabular}{lccc}
\hline Liquid & Density @ 20 $20^{\circ} \mathrm{C}$ & Viscosity @ 40 $0^{\circ} \mathrm{C}$ & Grade \\
\hline Engine oil & 0.866 & $65 \mathrm{~m}^{2} / \mathrm{s}$ & $5 \mathrm{~W}-30$ \\
\hline
\end{tabular}

its absorption capacity has been reported throughout the literature to the best of our knowledge. This present work evaluates the oil sorption capacity of unmodified empty fruit bunch fibre and how its efficiency is influenced by oil volume, time, and fibre weight for engine oil cleanup.

\section{Materials and Methods}

2.1. Materials. The empty fruit waste was obtained from the palm oil factory in the area of Jengka, Pahang State, Malaysia, Sea water was collected from the Danga bay beach in Johor Bahru, Malaysia, and was used at room temperature. New engine oil with the characteristics shown in Table 1 was used for the study.

2.2. Preparation of EPFB. The empty palm fruit bunch was chopped into smaller pieces and deoiled by soaking in hot deionized water with detergent for $24 \mathrm{hr}$. The sample was rinsed several times with distilled water to remove all debris and then air-dried at the ambient temperatures. The air-dried fibre was ground using electric blender and sieved to obtain a desired fibre size of $106 \mu \mathrm{m}$ as shown in Figure 1.

2.3. Absorbent Characterizations. The EPFB was observed by Philips XL40 scanning electron microscopy coupled with EDX model Philips XL 40 PW 6822/10 at an accelerating voltage of $15 \mathrm{kV}$. Before SEM examination, the samples were gold-coated with a thin layer of approximately $30 \mathrm{~nm}$ sputter coater with cool sputter coater (bio-rad) Edwards E2 M5. D5000 Siemens X-ray diffraction (XRD) machine was also used to examine the crystalline patterns of the fiber. The diffractograms were in the range of $2 \theta$ from $10^{\circ}$ to $60^{\circ}$ with $0.050^{\circ}$ steps at room temperature.

2.4. Oil Sorption Capacity. A $500 \mathrm{~mL}$ sample of sea water was placed in a $1 \mathrm{~L}$ glass beaker, $40 \mathrm{~mL}$ oil was added to the beaker, and the mixture was shaken. The dried fibre sample (1 g) was weighed in a steel mesh and then poured into the beaker containing the oil mixture in sea water. Shaking time was approximately 15 minutes at 105 cycles/min. Thereafter, the wetted fibre was weighed after being drained for $5 \mathrm{~min}$ in the oven [16]. The test was repeated three times in order to obtain the average values. The oil sorption of the sample was evaluated by weighing the samples before and after the absorption and determined by the formula:

$$
\text { Oil sorption capacity (OSC) : } \frac{[\mathrm{ST}-\mathrm{SC}-\mathrm{SA}]}{\mathrm{SA}} \text {. }
$$

SA is dry weight of sorbent (g), ST is total weight of oil (g), water, and dry sorbent, and SC is weight of water (g).

The experiment was repeated with varied oil volume, fibre's weight, and sorbent immersion durations.

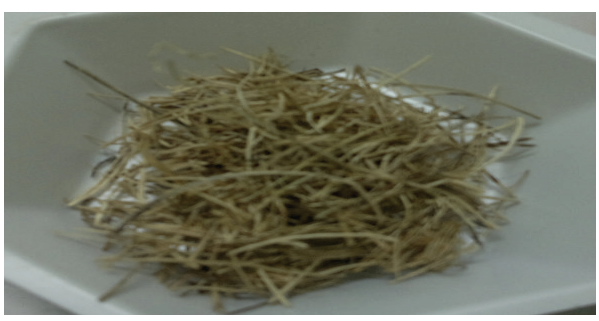

FIgURE 1: EPFB fibre.

2.5. Evaluation of Cyclic Sorption/Desorption Characteristic. The fibre was removed from the water/oil mixture systems with the aid of the mesh screen. The oil was then drained by squeezing the absorbed oil from the test cells manually after the amount of absorbed oil was determined. The weight of the test cells and the squeezed oil were measured in each cycle. The process was repeated until the sorption capacity result was less than $50 \%$ from the first cycle [17].

\section{Results and Discussion}

\subsection{Characterization}

3.1.1. SEM-EDX Study. Figures 2(a) and 2(b)-2(d) show the micrographs of EDX and SEM analyses, respectively; it is evident that EPFB fibre comprises numerous elements such as oxygen, sodium, carbon, sulphur, potassium, silicon and calcium with an approximated percentage quantity of 64.5 , $14,13.5,2.6,2$, 1.6, and 1.5, respectively. The SEM micrographs revealed that EPFB fibre contained numerous pores, which can transport and hold oil. The pores vary in sizes and are distributed over the silica craters present. The spiky whitish materials are silica bodies, and underneath are perforations, which aid oil sorption [18].

3.1.2. XRD Analysis. The XRD pattern of the EPFB is shown in Figure 3. It is observed that two broad peaks appear at $16^{\circ}$ and $23^{\circ}$ in the crystalline patterns which typify $\alpha$-cellulose XRD pattern [19]. The diffraction patterns at $2 \theta$ positions, $16.5^{\circ}, 22^{\circ}$, and $27^{\circ}$ show the presence of microcrystalline cellulose I and lignin as reported in [20].

3.2. Variation of Liquid Volume (Oil). The effect of oil volume on the oil sorption capacity was determined as shown in Table 2. The sorption capacity was evaluated as stated in Section 2.4.

From Figure 4, it is obvious that increment in oil quantity affects the absorption rate of the fibre. The sorption capacity was below $0.5 \mathrm{~g} / \mathrm{g} 5 \mathrm{~g} / \mathrm{g}$ for engine oil volumes ranging from 8 to $55 \mathrm{~mL}$. However, as the volume of oil was increased beyond $40 \mathrm{~mL}$, the rate of absorption increased significantly and reaches $2.07 \mathrm{~g} / \mathrm{g}$ of engine oil at $100 \mathrm{~mL}$.

3.3. Variation of Fibre Weight. The data of the effect of sorbent weight on sorption capacity is shown in Table 3.

The effect of fibre weight on the oil sorption capacity is illustrated in Figure 5. It was observed that oil sorption 


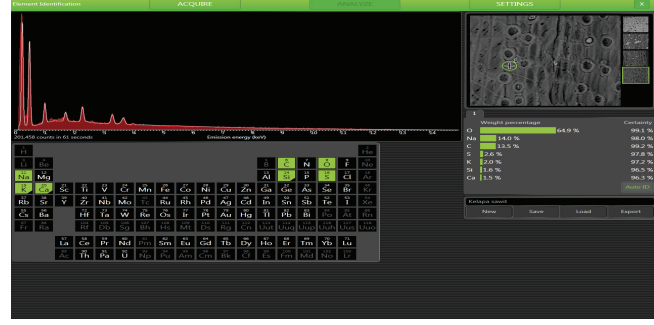

(a)

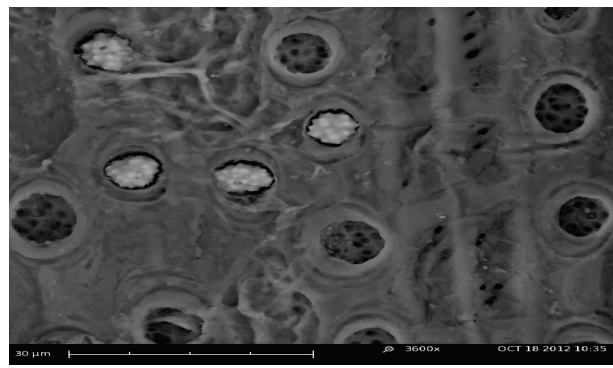

(c)

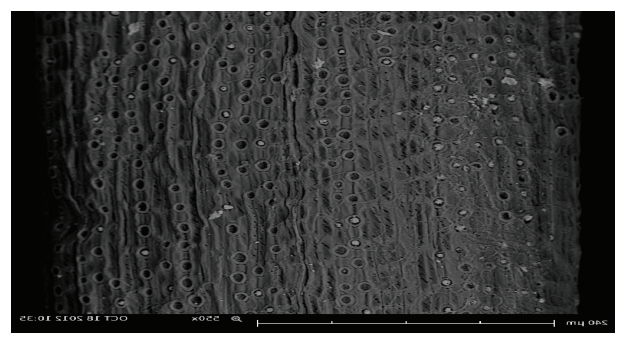

(b)

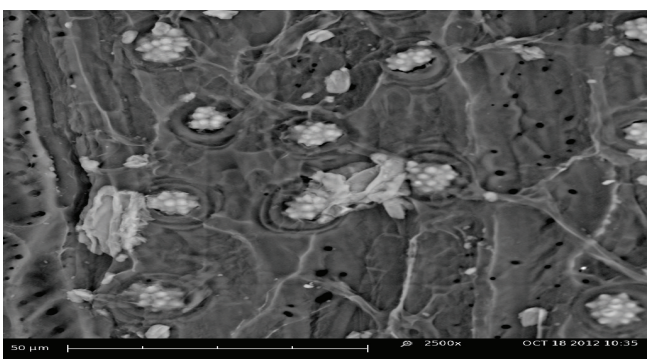

(d)

FIGURE 2: (a) EDX micrograph and (b-d) SEM micrographs of different magnifications.

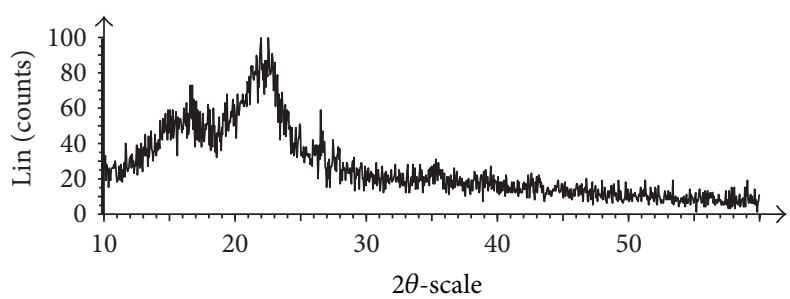

W Samp1-adila-file: samp1-adila.raw-type: $2 \mathrm{Th} / \mathrm{Th}$ lockedstart: $10.000^{\circ}$-end: $60.000^{\circ}$-step: $0.050^{\circ}$-step time: $1 . s$ temp.: $25^{\circ} \mathrm{C}$ (room)-time started: $2 \mathrm{~s}-2-\theta: 10.000^{\circ}$ $\theta: 5.000^{\circ}-\varphi: 0.00$

Operations: import

FIGURE 3: XRD patterns of EPFB fibre.

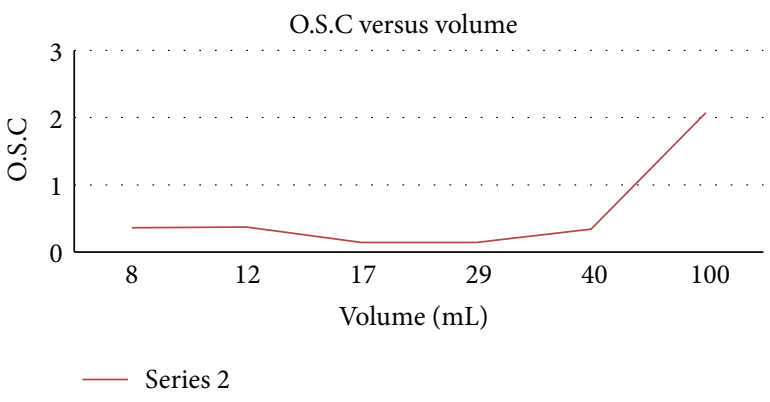

FIGURE 4: Oil sorption capacity versus liquid volume.

increased with increasing fibre weight. However, a further increasing in fibre weight above $3 \mathrm{~g}$ does not favour the rate of oil sorption capacity. The efficiency of sorption capacity depends on the fibre weight. The result showed that the sorption capacity of EPFB fibre decreased significantly from
TABLE 2: Data of the variation of liquid volume test.

\begin{tabular}{lcccc}
\hline$V / \mathrm{g}$ & SC & SA & ST & O.S.C \\
\hline 100 & 0.8312 & 1.0208 & 3.9662 & 2.0711 \\
40 & 0.8213 & 1.2842 & 2.5457 & 0.3428 \\
29 & 0.7990 & 1.1635 & 2.1330 & 0.1465 \\
17 & 0.8265 & 1.2434 & 2.2526 & 0.1469 \\
12 & 0.7794 & 1.2248 & 2.4598 & 0.3719 \\
8 & 0.7952 & 1.2663 & 2.5194 & 0.3616 \\
\hline
\end{tabular}

TABLE 3: Data of the variation of fibre weight test.

\begin{tabular}{lcccc}
\hline Wt. & SC & SA & ST & O.S.C \\
\hline$(1)$ & 0.8140 & 1.2463 & 2.3451 & 0.2285 \\
$(2)$ & 0.7954 & 2.0216 & 5.1449 & 1.1515 \\
$(3)$ & 0.8072 & 3.1163 & 8.0562 & 1.3262 \\
$(4)$ & 0.7987 & 4.2370 & 10.3800 & 1.2613 \\
$(5)$ & 0.7924 & 5.0658 & 11.5517 & 1.1239 \\
\hline
\end{tabular}

$1.33 \mathrm{~g} / \mathrm{g}$ to $1.12 \mathrm{~g} / \mathrm{g} 12 \mathrm{~g} / \mathrm{g} 12 \mathrm{~g} / \mathrm{g}$ at fibre weighed $3 \mathrm{~g}$ and $5 \mathrm{~g}$, respectively. This trend is similar to the effect of packing density on oil absorption capacity as reported in [20].

3.4. Variation of Time Consumed. Figure 6 shows the relationship between time and absorption capacity of EPBF. It is evident from the figure that there was no significant change in oil sorption within the first 60 minutes. However, there was a considerable increasing of oil sorption from $1.27 \mathrm{~g} / \mathrm{g}$ to $2.8 \mathrm{~g} / \mathrm{g}$ after $1 \mathrm{hr}$ and $4320 \mathrm{hr}$, respectively. 


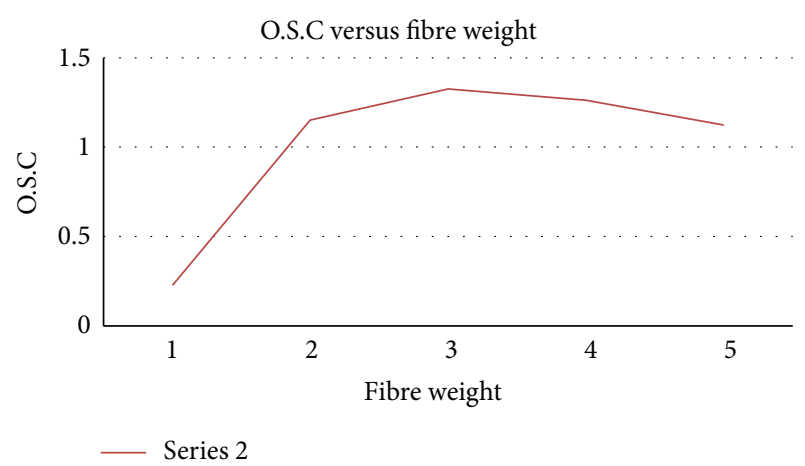

FIGURE 5: Oil sorption capacity versus fibre weight.

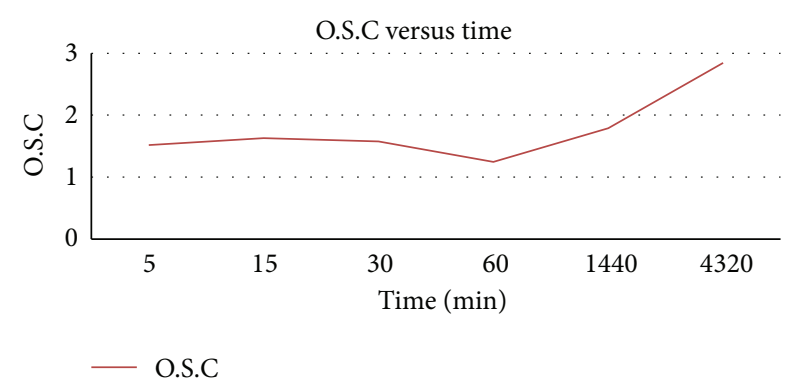

FIGURE 6: Oil sorption capacity versus time consumption.

\section{Conclusions}

Empty palm fruit bunches are generally disposed as wastes. The fibres are light weight, which promotes its buoyancy. From the preliminary study of this fibre, it can be concluded that EPFB can be used for oil cleanup. The use of the empty palm fruit bunch is environmentally friendly, sustainable, and economical. The residue of the oil-based sorbents of empty palm fruit bunch waste at the end of its life cycle can be used as high-energy fuel. However, the need for further research to investigate other characteristics besides the one presented throughout this study is essential.

\section{Conflict of Interests}

The authors declare that there is no conflict of interests regarding the publication of this paper.

\section{Acknowledgments}

The authors express their appreciation to the staff in the Department of Materials, Manufacturing and Industrial Engineering, Faculty of Mechanical Engineering and ISI, Universiti Teknologi Malaysia, for their financial and technical support. This work was partially supported by the Ministry of Higher Education of Malaysia (MOHE), Research Management Centre, Universiti Teknologi Malaysia, through GUP Grant no. 04H73.

\section{References}

[1] X.-F. Sun, R. C. Sun, and J. X. Sun, "A convenient acetylation of sugarcane bagasse using NBS as a catalyst for the preparation of oil sorption-active materials," Journal of Materials Science, vol. 38, no. 19, pp. 3915-3923, 2003.

[2] W. E. Lehr, "Containment and recovery devices for oil spill cleanup operations," Journal of Petroleum Technology, vol. 26, pp. 375-380, 1974.

[3] R. F. Johnson, T. G. Manjrekar, and J. E. Halligan, "Removal of oil from water surfaces by sorption on unstructured fibers," Environmental Science and Technology, vol. 7, no. 5, pp. 439-443, 1973.

[4] J. W. Smith, The Control of Oil Pollution, Graham \& Trotman, London, UK, 1983.

[5] W. S. Anthony, "Absorption of oil with cotton products and kenaf," Applied Engineering in Agriculture, vol. 10, no. 3, pp. 357361, 1994.

[6] W. T. Tsai, C. Y. Chang, S. Y. Wang, C. F. Chang, S. F. Chien, and H. F. Sun, "Utilization of agricultural waste corn cob for the preparation of carbon adsorbent," Journal of Environmental Science and Health B, vol. 36, no. 5, pp. 677-686, 2001.

[7] H.-M. Choi, "Needlepunched cotton nonwovens and other natural fibers as oil cleanup sorbents," Journal of Environmental Science and Health A, vol. 31, no. 6, pp. 1441-1457, 1996.

[8] T.-T. Lim and X. Huang, "Evaluation of kapok (Ceiba pentandra (L.) Gaertn.) as a natural hollow hydrophobic-oleophilic fibrous sorbent for oil spill cleanup," Chemosphere, vol. 66, no. 5, pp. 955-963, 2007.

[9] M. A. Abdullah, A. U. Rahmah, and Z. Man, "Physicochemical and sorption characteristics of Malaysian Ceiba pentandra (L.) Gaertn. as a natural oil sorbent," Journal of Hazardous Materials, vol. 177, no. 1-3, pp. 683-691, 2010.

[10] S. Kumagai, Y. Noguchi, Y. Kurimoto, and K. Takeda, "Oil adsorbent produced by the carbonization of rice husks," Waste Management, vol. 27, no. 4, pp. 554-561, 2007.

[11] K. Sathasivam and M. R. H. Mas Haris, "Adsorption kinetics and capacity of fatty acid-modified banana trunk fibers for oil in water," Water, Air, and Soil Pollution, vol. 213, no. 1-4, pp. 413423, 2010.

[12] M. O. Adebajo, R. L. Frost, J. T. Kloprogge, and S. Kokot, "Raman spectroscopic investigation of acetylation of raw cotton," Spectrochimica Acta A, vol. 64, no. 2, pp. 448-453, 2006.

[13] S. Suni, A.-L. Kosunen, M. Hautala, A. Pasila, and M. Romantschuk, "Use of a by-product of peat excavation, cotton grass fibre, as a sorbent for oil-spills," Marine Pollution Bulletin, vol. 49, no. 11-12, pp. 916-921, 2004.

[14] S. Shinoj, R. Visvanathan, S. Panigrahi, and M. Kochubabu, "Oil palm fiber (OPF) and its composites: a review," Industrial Crops and Products, vol. 33, no. 1, pp. 7-22, 2011.

[15] H. Moriwaki, S. Kitajima, M. Kurashima et al., "Utilization of silkworm cocoon waste as a sorbent for the removal of oil from water," Journal of Hazardous Materials, vol. 165, no. 1-3, pp. 266270, 2009.

[16] M. Hussein, A. Amer, and I. Sawsan, "Heavy oil spill cleanup using law grade raw cotton fibers: trial for practical application," Journal of Petroleum Technology and Alternative Fuels, vol. 2, no. 8, pp. 132-140, 2011.

[17] K.-N. Law, W. R. W. Daud, and A. Ghazali, "Morphological and chemical nature of fiber strands of Oil Palm Empty-Fruit-Bunch (OPEFB)," BioResources, vol. 2, no. 3, pp. 351-362, 2007. 
[18] C. T. Yu, W. H. Chen, L. C. Men, and W. S. Hwang, "Microscopic structure features changes of rice straw treated by boiled acid solution," Industrial Crops and Products, vol. 29, no. 2-3, pp. 308-315, 2009.

[19] M. Likon, M. Remškar, V. Ducman, and F. Švegl, "Populus seed fibers as a natural source for production of oil super absorbents," Journal of Environmental Management, vol. 114, pp. 158-167, 2013.

[20] M. A. Abdullah, A. U. Rahmah, and Z. Man, "Physicochemical and sorption characteristics of Malaysian Ceiba pentandra (L.) Gaertn. as a natural oil sorbent," Journal of Hazardous Materials, vol. 177, no. 1-3, pp. 683-691, 2010. 

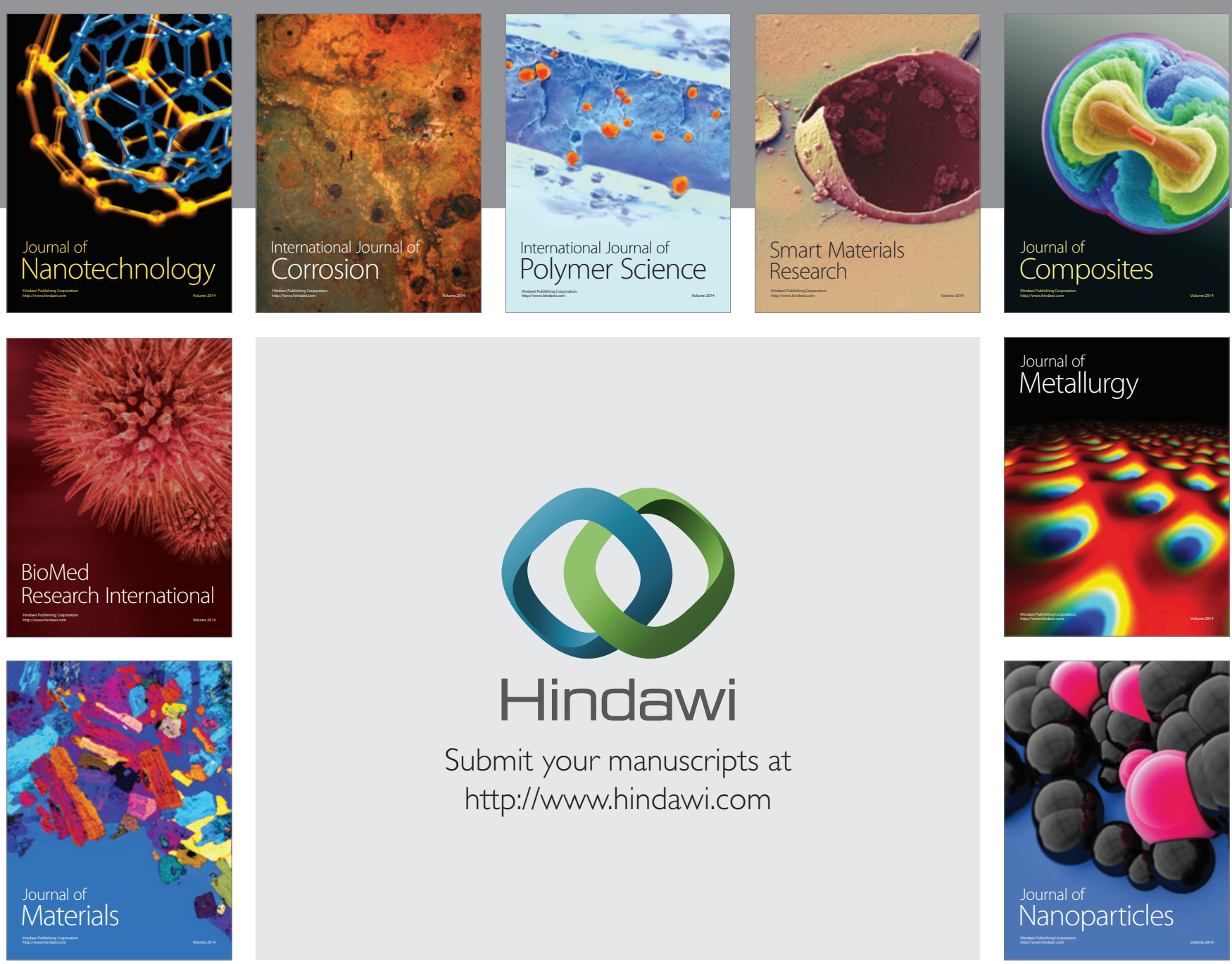

Submit your manuscripts at http://www.hindawi.com
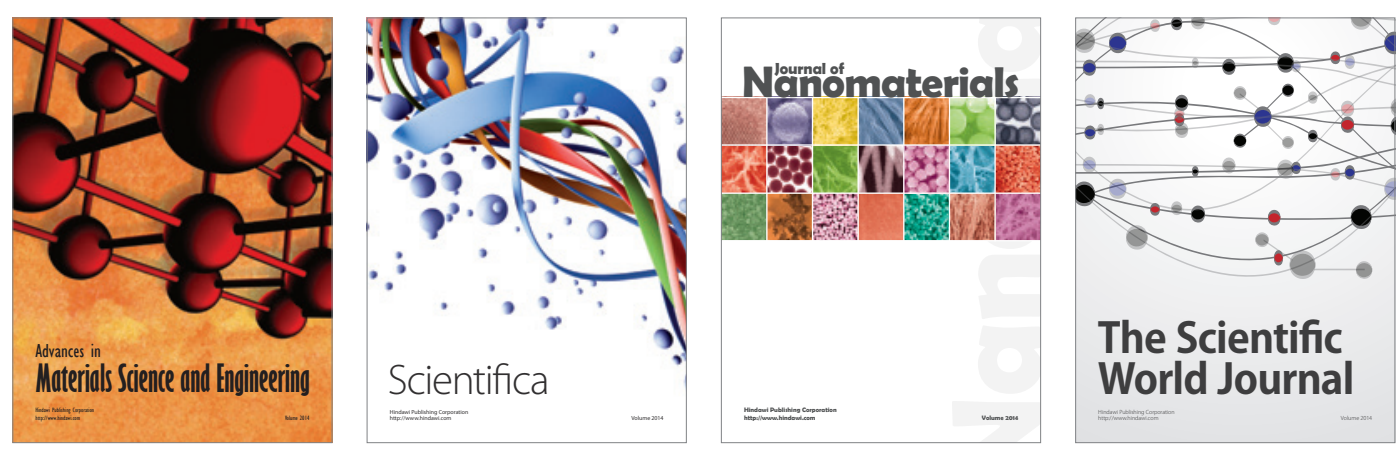

\section{The Scientific World Journal}
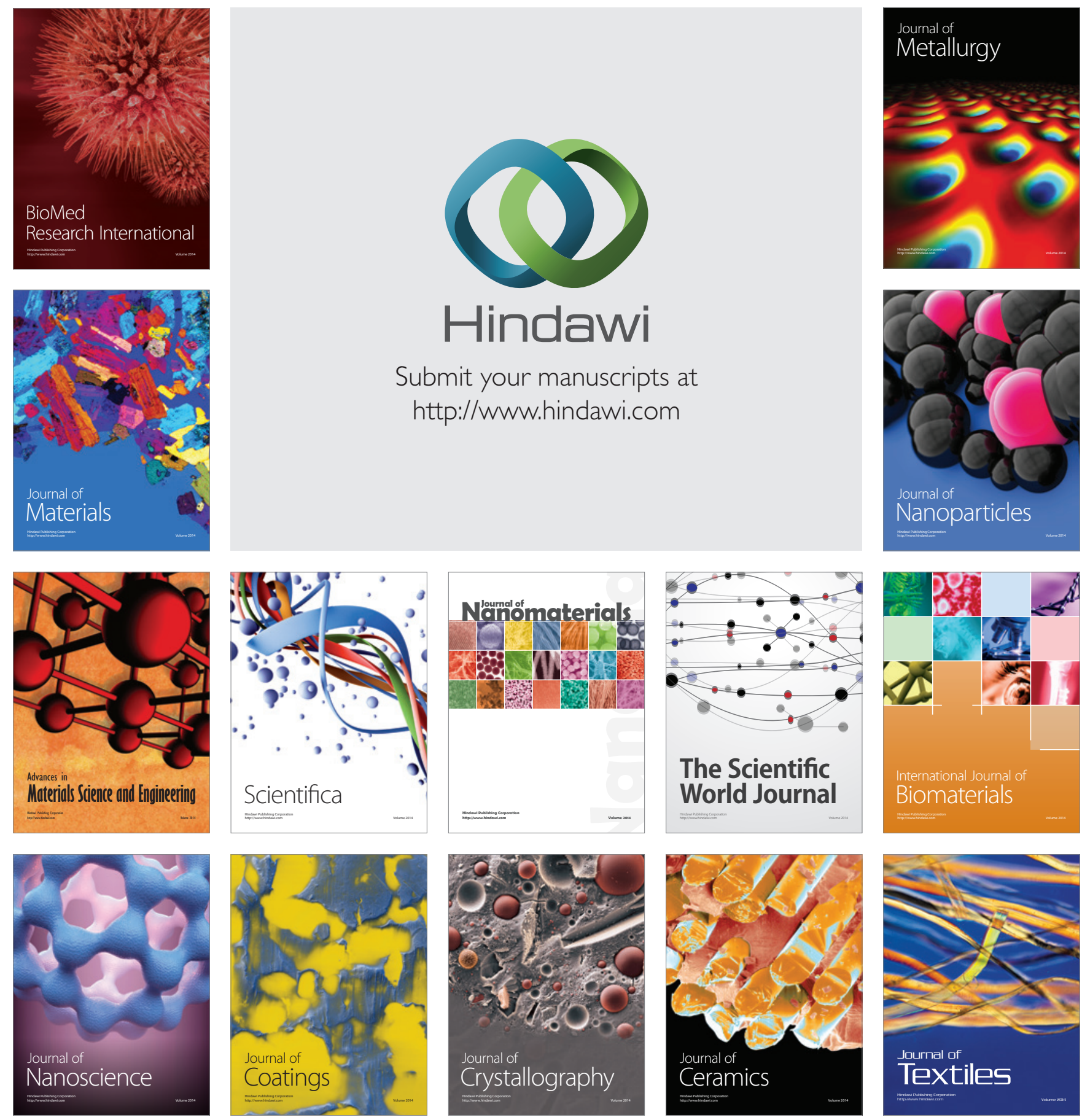